\title{
Impact of Cervical Cancer Preventive Education on the Practice of Cervical Cancer Routine Checks-Up
}

\author{
Dr. Ukeme E. Eyo, Dr. Memfin Ekpo \\ Department Of Physical And Health Education, University Of Uyo, Uyo \\ Department Of Pathology, University Of Uyo Teaching Hospital, Uyo Akwa Ibom State, Nigeria.
}

\begin{abstract}
The purpose of the study was to investigate the impact of cervical cancer preventive education on cancer routine check-up by women in Akwa Ibom State. A cross sectional survey design was used for this study. The population consisted of women between 16 and 45 years of age from three hospitals in Akwa Ibom State. A total of 314 women participated in the study. A researcher developed questionnaire "Impact of Cervical Cancer Preventive Education on Practice of Cervical Cancer routine Check up questionnaire (ICC PEPCCRCU) was used for data collection. Chi-square and simple regression were used to test the null hypotheses at .05 level of significant. The results showed no significant impact of level of education on knowledge of cervical cancer prevention, no significant impact of knowledge of practice of cervical cancer prevention. There was significant relationship between knowledge and practice of cervical cancer prevention. It was recommended that policy makers should employ professional health educators on cancer prevention to educate the women on cancer preventive measures.
\end{abstract}

\section{Introduction}

Cervical cancer is one of the leading causes of death in women in the developed countries. Screening programme help to identify pre-cancerous lesion at a stage when they can easily be treated. Lack of screening programme and routine checks-ups in poor countries lead to delay in identifying the cancer until it becomes too late and deadly. Inadequate cervical cancer preventive education leads to ignorance of the availability of screening services and patronage.

Many women are unaware of the need for cervical cancer screening and routine check ups. As such they do not patronize the few services available. Hassan ${ }^{(1)} 2001$ opined that the most important factor predicating the use of health services is that of knowledge.

Effective intervention against cervical cancer exist which is the screening and routine check ups, whereby the women are routinely screened against cervical cancer. Cancer screening using pap smear can identify precancerous and potentially precancerous changes in cervical cells and tissue (Demay ${ }^{(2)}, 2007$ ).

Cervical cancer is a malignant neoplasm arising from cells originating in cervix uteri (Gottlieb ${ }^{(4)}, 2002$ ). Infection which is sexually transmitted appears to be the factor in the development of almost all cases of cervical cancer and this can be prevented using HPV Vaccines (WHO ${ }^{(5)}, 2006$ ). intercourse.

One of the most common symptoms of cervical cancer is abnormal vagina bleeding usually after

Cervical cancer is a malignant neoplasm of the cervix uteri or cervical area. Cervical cancer preventative educators have been carried out during health talks in health facilities and peer education who are community members with the role of educating clients on cervical cancer basic information and care; have educated the women on cervical cancer prevention yet the burden of cervical cancer increases. Gottlied ${ }^{(4)}$ (2002) reported that $80 \%$ of cancer and deaths occur in women who live in developing world. Cervical cancer peaks at $35-45$ years of age. The same source revealed that approximately 250,000 women die per year from cervical cancer.

\section{Statement of the Problem}

Effective interventions against cervical cancer exist, including screening and routine check-ups for, and treatment of pre-cancer and invasive cancer in developed and developing world. United State preventive services task force's (USPSTF, 2013) recommendation is that a woman who have cervix, regardless of sexual history should be screened with pap smear for cervical cancer and should go for routine check ups every three (3) years especially ages 21 to 65 years.

Different studies conducted in different parts of the world have shown ignorance of cervical cancer prevention. For instance Regaswamy and Rajamanickam ${ }^{(8)}$ (2001) found out that cervical cancer remains largely uncontrolled in high risk developing countries. This high incidence was blamed on ignorance on the part of the women. From the above, the researcher raised this question, would enhancing, the knowledge women on cervical cancer preventive education influence the practice of routine check ups. 


\section{The Purpose of the Study}

The purpose of the study was to find the impact of cervical cancer preventive education on cervical cancer screening by women in Akwa Ibom State. Specifically the study sought to:

1) Determine the women's extent of knowledge of cervical cancer prevention,

2) Determine the women's extent of practice of cervical cancer screening and

3) Ascertain the influence of level of education on the knowledge of cervical cancer preventive education on the practice of cervical cancer screening.

\section{Research Hypotheses}

1. There is no statistically significant influence of level of education on the knowledge of cervical cancer prevention by women in Akwa Ibom State.

2. There is no statistically significant influence of level of education on the practice of cervical cancer screening by women in Akwa Ibom State.

3. There is no statistically significant relationship in the knowledge and by women in Akwa Ibom State.

\section{Research Design}

The Cross sectional survey research design was used for this study. This particular survey provides an opportunity for collection of data and seeking opinion from the representatives of the entire population.

\section{Population for the Study}

The Population for the study comprised women between 16 and 45 years of age in gynaecological clinic in three general hospitals in Akwa Ibom State.

\section{Sampling and Sampling Techniques}

For this study 314 women were drawn from three general hospitals representing the three senatorial districts of Akwa Ibom State. The women were classified according to their levels of education: Highly educated were women that have attended a form of tertiary institution. Women with low or no education were women that have attended Secondary School, Primary school or without any form of education.

The sample size was statistically determined using the formula for a finite population as follows:

$$
\begin{array}{ll}
\mathrm{n}=\mathrm{N} & \\
1+\mathrm{N}(\mathrm{e}) & \\
\text { Where } \mathrm{n} & =\text { sample size } \\
\mathrm{N} & =\text { Finite (population) } \\
\mathrm{e} & =\text { level of significant (.05) } \\
1 & =\text { Unity (Constant) }
\end{array}
$$

\section{Reliability of the Instrument}

The internal consistency of the instrument (ICPECCRCUQ) was determined through a trial test on a group of women of similar background to the study population.

\section{Hypothesis 1}

\section{Analysis And Interpretation Of Data}

There is no statistically significant influence of level of education on the knowledge at cervical cancer prevention by women in Akwa Ibom State.

TABLE 1

CHI-SQUARE ANALYSIS FOR THE INFLUENCE OF LEVEL OF EDUCATION ON THE PRACTICE OF CERVICAL CANCER PREVENTION BY WOMEN

\begin{tabular}{llll}
\hline Status & Acceptable & Not Acceptable & Total \\
\hline Highly Educated & $63(64.7)$ & $120(118.3)$ & 183 \\
Low Educated & $48(46.3)$ & $83(84.7)$ & 131 \\
Total & 111 & 203 & 314 \\
\hline
\end{tabular}

Note: Figure in parenthesis are expected frequencies 


\begin{tabular}{llll}
\hline $\mathbf{O}$ & $\mathbf{E}$ & $(\mathbf{O}-\mathbf{E})^{\mathbf{2}}$ & $\mathbf{X}^{\mathbf{2}}$ \\
\hline $\mathbf{6 3}$ & 64.7 & 0.04 & 0.15 \\
$\mathbf{1 2 0}$ & 118.3 & 0.02 & \\
$\mathbf{4 8}$ & 46.3 & 0.06 & \\
$\mathbf{8 3}$ & 84.7 & 0.03 & \\
\hline
\end{tabular}

$\mathrm{df}=1 \mathrm{P}=.05$ Chi Cri. 3.84

The data in table 1 show the analysis of influence of level of education on the knowledge of cervical cancer prevention by women.

The data show a calculated chi-score of .15 against the table value of 2.84 . Thus the null hypothesis was retained. There is no statistical influence of level of education on the practice of cervical cancer prevention by women

\section{Hypothesis 2}

There is no statistical significant influence on level of Education on the practice of cervical cancer by women in Akwa Ibom State.

TABLE 2

CHI-SQUARE ANALYSIS FOR THE INFLUENCE OF LEVEL OF EDUCATION ON THE PRACTICE OF CERVICAL CANCER SCREENING

\begin{tabular}{llll}
\hline Status & Acceptable & Not Acceptable & Total \\
\hline Highly Educated & $49(51.3)$ & $134(131.7)$ & 183 \\
Low Educated & $39(36.7)$ & $92(94.3)$ & 131 \\
Total & 88 & 226 & 314 \\
\hline & & & $\mathbf{X}^{\mathbf{2}}$ \\
\hline $\mathbf{O}$ & $\mathbf{E}$ & $\mathbf{( O - E ) ^ { \mathbf { 2 } }}$ & 0.34 \\
\hline $\mathbf{4 9}$ & 51.3 & 0.10 & \\
$\mathbf{1 3 4}$ & 131.7 & 0.02 & 0.14 \\
$\mathbf{3 9}$ & 36.7 & 0.06 & \\
\hline
\end{tabular}

$\mathrm{df}=1 \mathrm{P}=.5$ Chi Cri. 3.84

The data in Table 2 show the analysis of influence of level of education on the practice of cervical cancer screening. The data show a calculated of .34 against the table value of 2.84 . Thus the null hypothesis of the level of Education on the practice of cervical cancer screening was retained.

\section{Hypothesis 3}

There is no significant relationship in the knowledge and practice of cervical cancer screening by women in Akwa Ibom State.

Simple Regression Analysis was used on testing the hypothesis and summary data shown in Table 3

TABLE 3

Simple regression Analysis of the relationship between knowledge and practice of cervical cancer prevention

$\begin{aligned} \text { Regression Coefficient }(\mathrm{R}) & =.624 \\ \mathrm{R}^{2} & =.3894 \\ & =4.384\end{aligned}$

\section{Standard Error}

Analysis of Variance

\begin{tabular}{lcccc}
\multicolumn{1}{c}{ Source } & df & Sum of Square & Mean Square \\
Regression & 1 & 58.39 & 58.39 \\
Residual & 312 & 882.96 & 2.82 & 20.63 \\
Total & 313 & 941.35 & \\
\hline
\end{tabular}

Significant $\mathrm{P}<.05$

The null hypothesis was rejected since the computed F (20.63) was greater than the critical F (3.84) at df of 1.312 and .05 level of significant. Therefore, there was significant relationship between women's knowledge 
and practice of cervical cancer routine screening in Akwa Ibom State. The value of R2 ( .3894) indicated that $38.94 \%$ of the relationship was as a result of students knowledge.

\section{Hypothesis 1}

\section{Discussion of Findings}

Influence of Level of Education on the Knowledge of cervical Cancer Prevention

The analysis in table 1: Influence of level of education on knowledge of cervical cancer prevention revealed a calculated chi-square of .15 against a table value of 2.84 at df of 1 at .05 alpha level.

The results in hypothesis one revealed that there is no significant influence of level of education on the knowledge of cervical cancer prevention by women in Akwa Ibom State. The low level of knowledge of cervical cancer prevention among the women would probably have been due to inadequate educational programmes on cervical cancer prevention. This is in line with the findings of $\operatorname{Hassan}^{(9)}(2001)$ who opined, that the most important factor predicating the use of health services is that of knowledge.

Also the findings of Jumbo ${ }^{(10)}(2005)$ revealed that there was no use of health services in Calabar South Local Government Area of Cross River State, because of no health education on the matter. He opined that if people are made to know about the availability of any health service and are educated on the necessity of a particular health service, they would voluntarily adopt it.

It is obvious that though the women were highly educated, they did not posses adequate knowledge of cervical cancer prevention. Both the highly and lowly educated women lacked adequate knowledge of cervical cancer prevention.

\section{Hypothesis 2}

There is no statistical significant influence of level of education on the practice of cervical cancer screening by women in Akwa Ibom State.

The analysis for the influence of the level of education on practice cervical cancer screening revealed a calculated chi-score of .34 against the table value of 2.84 at $\mathrm{df}$ of 1 at .05 alpha level. This became obvious that the level of education of the women in Akwa Ibom State did not influence their patronage of cervical cancer screening services. Though one's level of education may influence the carrying out of worthwhile activities but in the case of health services if individual is not aware of the availability of the health services and awareness is not created on the need for those services, the individual may not adopt for the services. Sofuluwe, Schram and Ogunmekan ${ }^{(11)}$ (1998) posited that people's failure to take health precautions is as a result of their ignorance of what to do. They stated that lack of information and education on the available health services is the reason behind the consumer's failure to make maximum use of orthodox health services. This is confirmed by the assertion of Kalesanwo ${ }^{(6)}(2005)$ that performance of use depends on knowledge.

\section{Hypothesis 3}

There is no significant relationship in the knowledge and practice of cervical screening by women in Akwa Ibom State.

The findings in hypothesis three revealed that there is significant relationship between knowledge and practice of cervical cancer screening by women in Akwa Ibom state. This is in line with the finding of Kalesanwo that performance or use depends on knowledge. This is supported by the assertion of Alakija (2000) that adequate sensitization on any health programme enables the people to possess adequate knowledge on the programme, and thus patronize. If women are given adequate health education on cervical cancer screening/routine check ups they will patronize such health services. Women need to stay healthy, in order to take proper care of their children to fulfill the millennium development goals of reducing maternal and child mortality.

These findings provide some level of hope that with adequate cervical cancer preventive education, Nigeria and world at large will succeed in reducing cervical cancer burden among women.

\section{Conclusion}

Findings of the study, Impact of Cervical cancer preventive education on practice of routine check-up by women Akwa Ibom, revealed that there is no statistical influence of level of education on knowledge of cervical cancer routine check up, there is no statistical influences of level of education on practice of cervical cancer routine check up and there is significant relationship between women's knowledge and practice of routine check up in Akwa Ibom State.

\section{Recommendations}

1. Screening activities should be done at different levels of the health system.

At health centre 
- $\quad$ Extensive health education Campaign should be carried out by health personnel

- Health personnel all be trained on cervical cancer screening

- Health workers should screen all the women coming into the facility using the specified guideline.

- Screening services should be integrated into other services.

2. At the secondary and tertiary Health Care Facilities:

- Carry out screening services using the specified guideline

- Inform and counsel women with positive screening test result

- Counsel women diagnosed with cervical cancer to follow up diagnosis and treatment

- If the result of the test was negative the women should be informed of the need to return for a repeated screening.

- The government should move a policy that cancer screening should be free in order to allow its citizens access screening services

3. More community members should be trained as educators to educate the community members on the measures they can use to prevent cervical cancer.

4. Policy makers should employed professional health educators on cancer prevention to educate the women in cancer prevention.

\section{References}

[1]. Alakija, W. (2000). Essential of community health: Primary health Care and Health Management. Benin: Ambik Press

[2]. Demay, M. (2007). Practical of Cytophathology. Chicago: American Society for Clinical Pathology Press.

[3]. United States Preventive Services Task Force (2013). Screening for Cervical Cancer. Accessed 01-03-2009.

[4]. Gottlied, N. (2002). A Premier on Human Papilloma Virus. National Cancer Institute. Accessed 01-03-2009.

[5]. World Health Organization (2006). Comprehensive Cervical Control: A Guide to Essential Practice. Accessed 01-03-2009.

[6]. Kalensanwo, O. O. (2005). Assessment of Nutrition Knowledge and behaviour of Mothers in Ijebu - Igbo, Ogun State, Nigeria. Nigerian School Health Journal 17 (1 and 2), $169-174$.

[7]. Maureen, D. F. \& Briget, I. N. (2012). Cervical Cancer are you Sexually Active, have you been Screened? International Professional Nursing Journal 10 (1) $32-36$.

[8]. Rengaswamy S., Atul M. B. \& Rajamanickam R. (2001). Effective Screening Programmes for Cervical Cancer in Low and Middle Income Developing Countries

[9]. Hassan, U. (2001). Strenghtening the Utilization of Primary Health Care Services Through Increase Health Education Activities. Nigerian School Health Journal, 13 (1 \& 2), $104-110$

[10]. Jumbo, E. A. (2005). Knowledged and Practice of Roll back Malaria among Secondary School Students in Calabar. An Unpublished Masters Degree Thesis, University of Calabar

[11]. Sofoluwe, S. \& Ogunmekan (1998). Principle and Practice of Public Health in Africa (1) Ibadan: University Press. 